\title{
Ectopic expression of a small cell lung cancer transcription factor, INSM1 impairs alveologenesis in lung development
}

\author{
Chiachen Chen ${ }^{1,2}$, Mary B. Breslin ${ }^{1,2}$ and Michael S. Lan ${ }^{1,2,3^{*}}$
}

\begin{abstract}
Background: Insulinoma associated-1 (INSM1) gene is expressed exclusively in early embryonic neuroendocrine tissues, but has been found highly re-activated in most of the neuroendocrine tumors including small cell lung carcinoma.

Methods: In order to elucidate the functional effects of INSM1 in normal lung development, we used a conditional lung-specific INSM1 transgenic mouse model. Transgenic (Tet-on system) CMV-INSM1 responder mice were bred with the lung-specific, club cell secretory protein (CCSP) promoter-rtTA activator mice to produce bi-transgenic progeny carrying both alleles, CCSP-rtTA and Tet-on-INSM1. Mice were fed with doxycycline containing food at the initial mating day to the postnatal day 21. Lung samples were collected at embryonic day 17.5, newborn, and postnatal day 21 for analyses.

Results: Northern blot, RT-PCR, and immunohistochemical analyses revealed that doxycycline induced respiratory epithelium-specific INSM1 expression in bi-transgenic mice. Samples from postnatal day 21 mice revealed a larger lung size in the bi-transgenic mouse as compared to the single-transgenic or wild-type littermates. The histopathology results showed that the alveolar space in the bi-transgenic mice were 4 times larger than those in the single transgenic or wild-type littermates. In contrast, the size was not significantly different in the lungs collected at E17.5 or newborn among the bi-transgenic, single transgenic, or wild type mice. The respiratory epithelium with INSM1 ectopic expression suppressed cyclin D1 signal. Further in vitro studies revealed that the ectopic expression of INSM1 suppresses cyclin D1 expression and delays cell cycle progression.
\end{abstract}

Conclusion: The current study suggests that CCSP promoter-driven INSM1 ectopic expression impairs normal lung development especially in postnatal alveologenesis.

Keywords: INSM1, SCLC, CCSP, Alveologenesis, Lung development, Transgenic model, Cyclin D1

\section{Background}

The lung produces more than 40 cell types to fulfill the important functions in mucociliary clearance, gas exchange, metabolism, and endocrine activities. The major cell types in lung epithelium include ciliated cells, basal cells, type I and II pneumocytes, club cells, and neuroendocrine (NE) cells [1]. Although pulmonary neuroendocrine cells (PNECs) are the first specialized cell type within the bronchial epithelium with progenitors of $\mathrm{NE}$

\footnotetext{
* Correspondence: mlan@lsuhsc.edu

'Research Institute for Children, Children's Hospital, 200 Henry Clay Avenue, Research and Education Building, Room. 2211, New Orleans, LA 70118, USA ${ }^{2}$ Departments of Pediatrics, Louisiana State University Health Sciences Center, New Orleans, LA 70112, USA

Full list of author information is available at the end of the article
}

nature, their presence in lung are relatively scarce. Usually, a single pulmonary NE cell is scattered in the respiratory epithelium. Clustered PNECs, also called neuroepithelial bodies (NEBs) are commonly found at bronchioalveolar duct junctions. The ontogeny of PNECs and their relationships to other lung cells during normal homeostasis, lung injury, and late stages of lung development are still unclear. In naphthalene-induced lung injury, most club cells were damaged by the drug whereas those located nearby NEBs survived and were capable of restoring the damaged lung epithelium. These results suggest that the potential function of PNECs is to maintain the stem cell niches required for club cell regeneration and injury repair [2,3]. 
Insulinoma associated-1 (IA-1/INSM1) was originally cloned from a human insulinoma subtraction library [4]. It was mapped to chromosome 20p11.2 as an intronless gene that translates into a protein of 510 amino acids and a predicted molecular mass of 52,923 $\mathrm{Da}$ [5]. INSM1 gene is expressed exclusively during early embryonic NE development, but has been found highly reactivated in NE tumors [6]. INSM1 is a sensitive marker for NE differentiation in human lung tumors. INSM1 mRNA was detected by Northern blot analysis in $97 \%$ (30 of 31) of small cell lung cancer cells and $13 \%$ (4 of 30) of non-small cell lung cancer cells with NE phenotype. In most of the lung cancer cells examined, INSM1 expression showed high concordance with the other specific NE markers, synatophysin, L-dopa decarboxylase, and chromogranin A [7, 8]. An aggressive type of NE tumor, small cell lung carcinoma (SCLC) accounts for approximately 10 to $15 \%$ of all lung cancers. INSM1 can be detected at high levels in most of the SCLC cancer tissues [7].

In order to determine the effect of INSM1 on normal lung development, we generated a conditional lungspecific INSM1 transgenic mouse model. In this model, the ectopic expression of INSM1 was selectively induced in non-ciliated bronchial epithelial club cells. Transgenic Tet-on-INSM1 responder mice were bred with the lungspecific, club cell secretory protein (CCSP) promoterrtTA activator mice to generate bi-transgenic progeny carrying both alleles, CCSP-rtTA and Tet-on-INSM1. In this bi-transgenic model, INSM1 expression is induced by doxycycline (Dox) bound to rtTA, which in turn activates the Tet-on-CMV promoter, activating transcription of the INSM1 gene. Our model provides a tool to elucidate the effect of INSM1 on PNECs. In the present study, we found that ectopic expression of INSM1 in bronchiolar epithelial cells impairs alveolarization resulting in alveolar space enlargement at the end stage of lung development. Ectopic expression of INSM1 inhibits cyclin D1 expression in the INSM1/rtTA bi-transgenic mouse bronchiolar epithelium and delays cell cycle progression. Our results suggest that INSM1 not only plays a role in alveolar septation, but also indicates that INSM1 might have profound effects on PNECs proliferation and club cell regeneration when pulmonary epithelium was damaged.

\section{Methods}

\section{Animals and genotyping}

For (tetO) ${ }_{7}$ CMV-INSM1 mice, a human INSM1 fulllength cDNA $(2.8 \mathrm{~kb})$ was sub-cloned into a pBI-EGFP Tet vector containing the CMV promoter and tetracycline response element. The transgenic animal model was generated from Gene Targeting \& Transgenic Facility, University of Connecticut Health Center (Farmington, CT).
Two lines of transgenic mice bearing (tetO) ${ }_{7} \mathrm{CMV}$-INSM1 transgene were generated. The lung-specific Dox inducible CCSP-rtTA ${ }^{-/ t g}$ transgenic line was obtained from Jackson laboratory. Bi-transgenic mice, named INSM1/ $r t T A$, were generated by crossing (tetO) $)_{7}$ CMV-INSM1 and CCSP-rtTA ${ }^{-/ t g}$. Wild type littermates lacking either rtTA or INSM1 allele were used as control. Transgenic mice were genotyped by PCR using genomic DNA from tail of fetal or postnatal mice. PCR primers for transgenes were: for CCSP-rtTA, forward primer 5'-ACT GCCCATTGCCCAAACAC-3'; reverse primer: 5'-AAA ATCTTGCCAGCTTTCCCC-3', for (tetO) 7 CMV-INSM1, forward primer: 5'-CCTTGTACAACCGACAGCTC-3', reverse primer: 5'-GAGTGAGCTGATACCGCTCG-3'. The PCR amplification was performed as follow: denatured at $95{ }^{\circ} \mathrm{C}$ for 3 mins followed by 35 cycles of amplification at $95{ }^{\circ} \mathrm{C}$ for 30 s, $58{ }^{\circ} \mathrm{C}$ for $30 \mathrm{~s}$ and extension at $72{ }^{\circ} \mathrm{C}$ for 30 s. Animals were maintained in a pathogen-free vivarium in filtered cages according to the protocol approved by Institutional Animal Care and Use Committee from the Research Institute for Children, Children's Hospital in New Orleans. All mice were maintained in C57BL/6 background. Dams bearing double transgenes were fed with Dox food (200 mg/kg; Bio Serv co., Frenchtown, NJ) for various time spans.

\section{Cell Culture}

A human normal bronchial epithelial cell line, BEAS-2B was obtained from American Type Culture Collection. The cells were cultured in Dulbecco's modified Eagle's medium (DMEM, high-glucose) with $10 \%$ fetal calf serum (Atlanta Biological Inc., Norcross, Georgia), 1X Pen/Strep (10,000 IU penicillin and 10,000 ug/ml streptomycin) (Mediatech, Inc., Manassas, VA.) in a $5 \%$ $\mathrm{CO}_{2}$ incubator at $37^{\circ} \mathrm{C}$.

\section{MTS assay}

The 3-(4,5-dimethyl-2-yl)-5-(3-carboxymethoxyphenyl)-2(4-sulfophenyl)-2H-tetrazolium, inner salt, MTS proliferation assay was carried out according to the manufacturer's protocol (Promega Co., Madison, WI). The cells were seeded and infected with Ad-LacZ or Ad-INSM1 virus in a serum-free medium for $24 \mathrm{~h}$ and then cultured in Dulbecco's modified Eagle's medium (DMEM, highglucose) with $10 \%$ fetal calf serum. After culturing for 48 or $60 \mathrm{~h}$, CellTiter $96^{\circ} \mathrm{AQ}_{\text {ueous }}$ One Solution Reagents were added into the culture medium and then incubated at $5 \% \mathrm{CO}_{2}, 37^{\circ} \mathrm{C}$ for $4 \mathrm{~h}$. The amount of soluble formazan produced by cellular reduction of MTS was measured for absorbance at $490 \mathrm{~nm}$ using a microplate spectrophotometer to calculate the cell viability. 


\section{RNA isolation and Northern blot analyses}

Lung RNAs were extracted using TRIzol reagent (Life Technologies, San Francisco, CA) following the manufacturer's instruction. RNA was treated with 2 units of DNase (Promega Co., Madison, WI) at $37{ }^{\circ} \mathrm{C}$ for $30 \mathrm{~min}$ to remove residual genomic DNA. Total lung RNA was used as template to synthesize cDNA by High Capacity RNA-to-cDNA ${ }^{\text {Tw }}$ Kit (Life Technologies, San Francisco, CA) following the manufacturer's protocol. RNA was reverse transcribed and analyzed by PCR and/or real-time PCR for the expression of INSM1 and cyclin D1. The relative RNA concentration of the target gene was normalized to the concentration of the housekeeping gene, GAPDH. Primers for INSM1: INSM1440aa 5'-ACGGAATTCTGCCACCTGTGCCCAGTGT GCGGAGAG-3', INSM-510aa 5'-CACCTCGAGCTAGCA GGCCGGGCGCACGGGCACCTGCAG-3' Primers for cyclin D1, forward 5'-TGCCTACAGCCCTGTTACCT-3' and reverse 5'-ACTTTGCAGGACAGATCCCG-3'. Total RNA (20 ug) was separated on $1 \%$ agarose/formaldehyde gel. The gel was transferred to a nitrocellulose membrane for $3 \mathrm{~h}$ in 20X SSC and then UV crosslinked. The membrane was pre-hybridized in Express Hybe Solution (Clontech, Mountain View, CA) for $1 \mathrm{~h}$ followed by hybridization in the same solution with ${ }^{32} \mathrm{P}$-labeled INSM1 probe, washed, and exposed to autoradiography.

\section{Western blot analyses}

Cell lysates were extracted with the lysis buffer $(10 \mathrm{mM}$ Tris- $\mathrm{HCl} \mathrm{pH} \mathrm{7.5,} 150 \mathrm{mM} \mathrm{NaCl}, 10 \%$ glycerol, 1 \% Triton X-100, $1 \mathrm{mM}$ DTT, $0.2 \mathrm{mM}$ PMSF, $1 \mathrm{ug} / \mathrm{ml}$ aproptinin, $1 \mathrm{ug} / \mathrm{ml}$ leupeptin, $1 \mathrm{mM} \mathrm{Na} \mathrm{VO}_{4}$ and $1 \mathrm{mM} \mathrm{NaF}$ ), separated on $10 \%$ SDS-PAGE gel, and transferred onto the nitrocellulose membrane (Bio-Rad Laboratories, Inc., Hercules, CA). The membrane was blocked with $5 \%$ BSA in TBST $(20 \mathrm{mM}$ Tris- $\mathrm{HCl} \mathrm{pH} 7.6,137 \mathrm{mM} \mathrm{NaCl}$ and $0.1 \%$ Tween-20), probed with specific primary antibody at $4{ }^{\circ} \mathrm{C}$ overnight, and bound with HRP-conjugated secondary antibody (Bio-Rad) at room temperature for $1 \mathrm{~h}$. The membrane was developed with a chemi-luminescence substrate (Bio-Rad Laboratories, Inc., Hercules, CA), and the blot was autographed onto a X-ray film (Fuji Photo Film Co., Japan).

\section{Histology and immunohistochemistry}

Human small cell lung carcinoma tissue array (LC802b) was used in this study. Each specimen collected from any clinic was consented to by both hospital and individual. Discrete legal consent form was obtained and the rights to hold research uses for any purpose or further commercialized uses were waived (US Biomax, Rockville, MD). An IRB exemption (\#8885) was obtained from Louisiana State University Health Sciences Center, New Orleans. Mouse tissue sections were prepared from fetal (E17.5), neonatal (newborn and postnatal days 7, PN7), and 3-week old mice (PN21) fixed with $4 \%$ paraformaldehyde in phosphate-buffered saline (PBS) at $4{ }^{\circ} \mathrm{C}$. Tissue sections were stained by hemotoxylin and eosin (H\&E staining) for the histopathology study. For immunohistochemistry, sections were blocked with $5 \%$ BSA in PBS and incubated with either anti-CCSP, synatophysin, or cyclin D1 antibody (Cell Signaling Technology, Beverly, MA) at $4{ }^{\circ} \mathrm{C}$ overnight. Then, the slides were incubated with secondary antibodies conjugated with HRP for $1 \mathrm{~h}$ at room temperature and developed using a diaminobenzidine (DAB) histochemistry kit (Life Technologies, San Francisco, CA). For immunohistochemical staining of INSM1, anti-INSM1 antibody (Santa Cruz biotechnology, Inc., CA) with a $\mathrm{MACH} 3$ biotin free polymer detection kit was used on the human tissue array slide and Mouseon-Mouse HRP-polymer bundle kit were used on mouse tissue sections (Biocare Medical, Concord, CA).

\section{Lung morphometric analysis}

For preparing the mouse lung samples, we euthanized mice with overdosed ketamine/xylazine, open the chest cavity, removed the sternum and ribs to expose the heart. We inserted the butterfly needle into the right ventricle and nicked at the right atrium to build a direct route to pulmonary circulation for lung perfusion and fixation with cold PBS and formalin. After perfusion, we injected $2 \mathrm{ml}$ of $10 \%$ formalin into trachea to fix and inflate the lung. The dissected lungs were measured by weight. The preserved lung samples were subjected to histological analysis. Lung tissue sections were stained with hematoxylin and eosin. Sections were visually scanned for position-matching regions compared with controls. At least four representative lobes were selected from each animal. A Kodak MI image system was used to measure terminal air space area. We drew the outline of the alveoli and used software to measure the area size at 200X magnification. For each sample, we measured 4 fields and each field at least 20 alveoli. The air spaces were distinguished from tissue based on intensity and the number of pixels acquired for each air space when converted to square micrometers.

\section{Flow cytometry}

The cells were seeded and infected with Ad-LacZ virus or Ad-INSM1 virus for 48 or $96 \mathrm{~h}$. Cells were collected and fixed with cold $70 \%$ ethanol at $4{ }^{\circ} \mathrm{C}$ overnight. The fixed cells were washed twice with PBS and then the cells were incubated in PI staining solution (PBS with $0.2 \mathrm{mg} / \mathrm{mL}$ DNase-free RNase, $0.1 \%$ Triton X-100, and $1 \mathrm{mg} / \mathrm{mL}$ propidium iodine) at room temperature for $30 \mathrm{~min}$ before analysis on the flow cytometer. 


\section{Statistical analysis}

Values were corrected and expressed relative to an control group. All experiments were repeated three times. Results are presented as mean \pm SD. Statistical analysis was performed using either the Student's t-test when only two groups were in the experiment or by an oneway ANOVA comparison of multiple groups using the Tukey-Kramer test with differences at $p$ value of less than 0.05 being considered significant.

\section{Results}

\section{INSM1 is a sensitive small cell lung cancer marker}

Small cell lung cancer tumors are derived from pulmonary NE cells (PNECs), therefore their antigenic profile coincides with that of NE cells. In this study, we used immunohistochemical staining to examine 35 cases of different clinical stages of small cell lung cancer and 5 normal lung tissues for INSM1 expression. All the small cell lung cancer tissues were strongly positive for INSM1. INSM1 signal was not detected on normal adjacent tissues from lung cancer patients or normal lung tissues (Fig. 1). The expression pattern of INSM1 in NE lung cancer is consistent with the previous Northern blot analysis that revealed INSM1 mRNA is highly expressed in nearly $100 \%$ of small cell lung carcinomas (SCLC) cell lines but not in normal adult lung tissues $[6,7]$. Here, we showed that the INSM1 protein is highly over-expressed in 35 SCLC tumor tissues confirming that INSM1 is a specific and sensitive NE marker of small cell lung cancer. However, the functional role of INSM1 in NE lung cancer or normal lung in PNEC development is still unclear.

\section{Ectopic expression of INSM1 in bi-transgenic animals}

In order to determine the effect of INSM1 in normal lung development, we used a conditional lung-specific INSM1 transgenic mouse model. Transgenic Tet-onINSM1 responder mice were bred with the lung-specific, club cell secretory protein (CCSP) promoter-rtTA activator mice to generate bi-transgenic progeny carrying both alleles, CCSP-rtTA and Tet-on-INSM1 (Fig. 2a). In this bi-transgenic model, INSM1 expression is induced by binding the tetracycline analogue Dox to rtTA, which in turn activates the Tet-on-CMV promoter and the transcription of INSM1 gene. Dox containing food was fed from the initial mating day to the weaning day (postnatal day 21, PN21) to ensure the full effect of INSM1 expression during lung development. Lung samples were collected at embryonic day (E) 17.5, newborn (PN0), and 3-week wean day (PN21). INSM1 was selectively expressed in a subset of respiratory epithelial cells, bronchial, and type II epithelial cells of lung tissues. The ectopic over-expression of INSM1 was spatially and temporally under the control of the lung specific
CCSP-promoter and Dox. Two Tet-on-INSM1 transgenic lines (named 14-4-5 and 14-2-2) were generated and included in this study. Previous studies indicated that the CCSP-promoter directs rtTA transgene expression as early as post-conception day 14, E14 [9]. To ensure the fidelity of our transgenic system in regulating INSM1 expression, we treated the bi-transgenic (INSM1/rtTA), single transgenic (INSM1 or $r t T A$ ), and wild type mice with Dox food from the beginning of conception day. At each time point, E17.5, newborn (PN0), postnatal day 7 (PN7), and postnatal day 21 (PN21), the lung tissues were collected and subjected to Northern blot analyses, RT-PCR, real-time PCR, and immunohitochemical staining for INSM1 expression (Fig. 2). The results revealed that Dox food induced respiratory epithelium-specific INSM1 over-expression in the bi-transgenic mice as compared to single transgene, or wild-type littermates (Fig. 2b and e). INSM1 over-expression was detected in both lines of bi-transgenic lung tissues under Dox induction. Without Dox induction there was no INSM1 signal in bi-transgenic lung tissues (Fig 2c). The INSM1 expression level varies in different bitransgenic animals (Fig. 2d). Since the over-expression of INSM1 is under the control of CCSP-promoter, the immunohistochemical staining showed that INSM1 overexpression was co-localized with CCSP expressing cells (Fig 2f). We performed the immunohistochemical staining of transgenic mouse tissues with anti-CCSP, anti-INSM1, or anti-synaptophysin antibody using the consecutive tissue sections from PN21 $\mathrm{Bi}-\mathrm{Tg}$, and PN7 CTRL lungs (Fig. 2e, f, g). We observed that a few bronchiolar epithelial cells with synaptophysin signal are CCSP-positive on the CTRL mouse lung section (Fig. 2g). On PN21 Bi-Tg lung section, INSM1-positive cells are also CCSP positive (Fig. 2f). We detected ASCL-1 and INSM1 expression on the consecutive tissue sections from E17.5 wild type and Bi-Tg lungs (Fig. 2h). The ASCL-1 positive cells are INSM1-positive. Synaptophysin and ASCL-1 are well known NE cell markers and were used as PNEC markers. The bi-transgenic lung was subjected to a time course study (Fig. 3a). The INSM1 transcript is expressed in all four time points, from E17.5, PN0, PN7, to PN21. Among the lung tissues that we collected from both lines of animals, the expression of transgenic INSM1 was significantly increased with age at the RNA level (Fig. 3b). The immunohistochemical staining of INSM1 showed that the over-expression of INSM1 on bronchial epithelial cells of bi-transgenic mice is consistently positive from embryonic stage (E17.5) until PN21. However, INSM1 expression in normal lung is only scarcely detected in E17.5 fetal lung (Fig. 3c). Although overexpression of INSM1 mRNA was increased by age, the protein levels were not significantly increased in a time-dependent manner. 

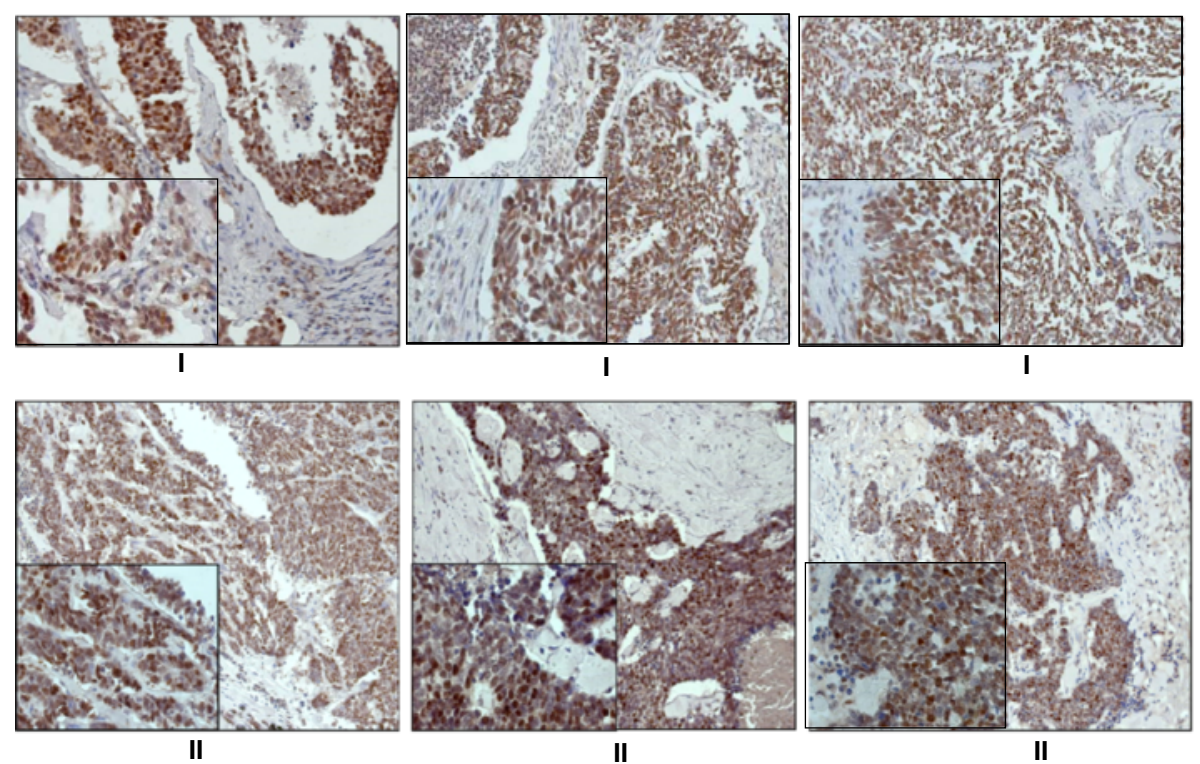

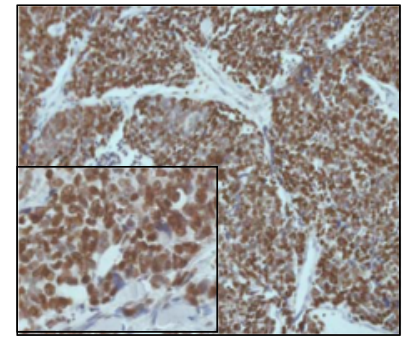

IIIA

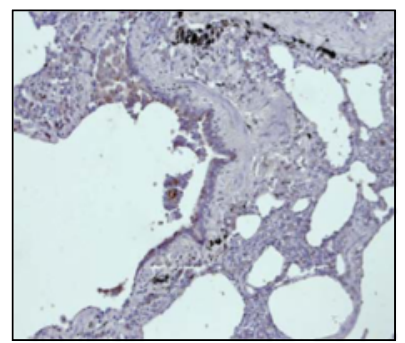

NAT

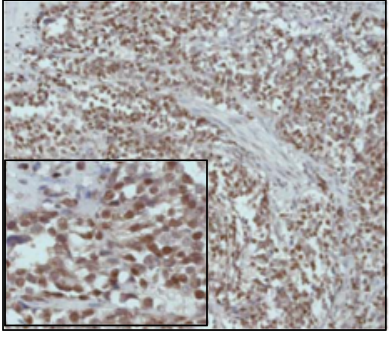

IIIB

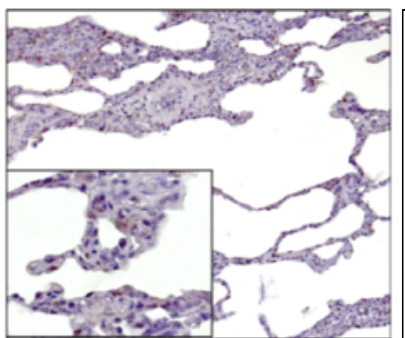

NAT

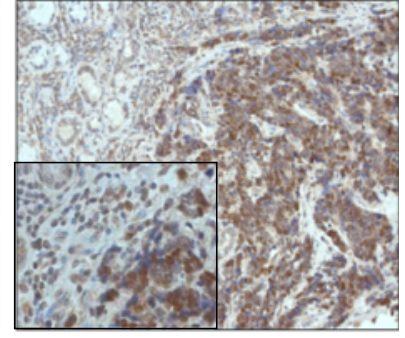

IIIB

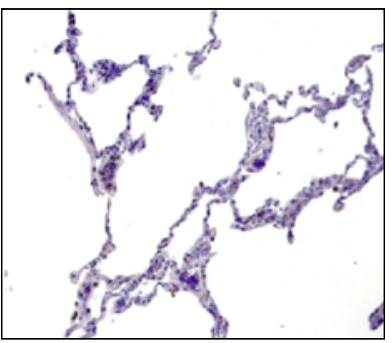

Normal Lung

Fig. 1 INSM1 staining of small cell lung cancer tissue array. Nine slides were selected from 35 cases of SCLC tissues (include clinical stages I, II, IIIA, and IIIB) and 3 normal lung tissues. Tissue array was immunostained with anti-INSM1 antibody. NAT: lung normal adjacent tissue. Original magnification is $200 \mathrm{X}$ and $400 \mathrm{X}$ (inset)

\section{INSM1 expression alters lung morphology}

We examined the lungs for any gross morphological abnormalities. Samples from PN21 mice revealed that the lung size of bi-transgenic mice is $40 \%$ larger than the control littermates (Fig. 4a and b). However, the size is not significantly different in the lungs collected from E17.5 or PN0 among the bi-transgenic, single transgenic, and wild type mice (data not shown). Similarly, histological analysis of the pulmonary structure at E17.5 shows no defect in lung morphology (Fig. 4c and d). In contrast, the histopathological data revealed that the alveolar space in the bi-transgenic mice were significantly larger than those in the single transgenic or wild-type littermates at PN21 (Fig. 4e). After quantification with Kodak MI SE software and statistical analysis, the average alveolar space of the bi-transgenic mice is five times larger than control (Fig 4f). This observation indicates that ectopic expression of INSM1 disrupts alveolar septation that causes air space enlargement. It is likely that the INSM1 expression interrupts the 


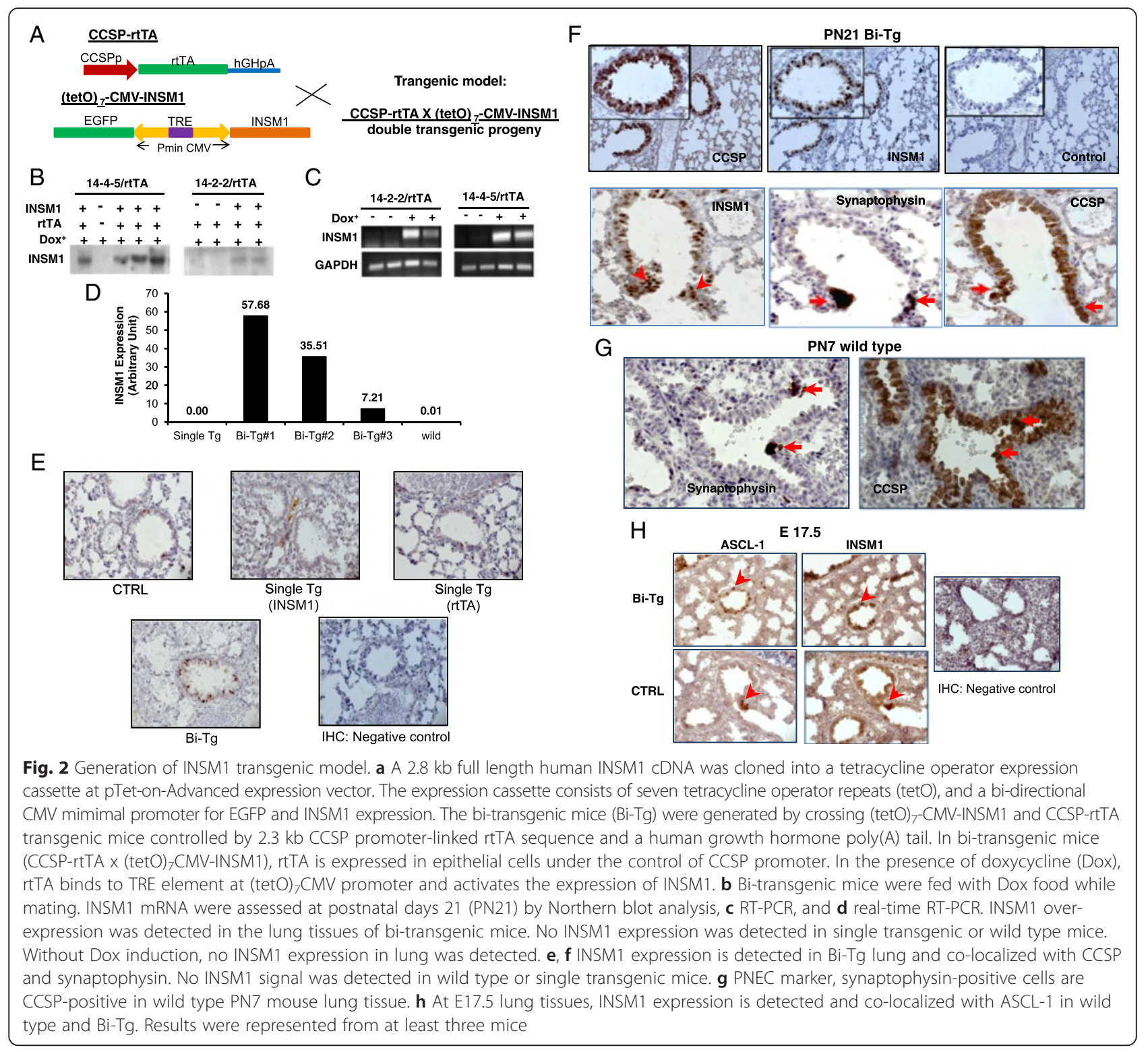

last alveolar stage development in the bi-transgenic animal lung.

\section{INSM1 suppresses cyclin D1 expression in lung development}

Immunohistochemical staining of control or bi-transgenic lung for cyclin D1 revealed that bi-transgenic lung has a weaker signal in the nuclei of bronchial epithelial cells and respiratory bronchiole epithelial cells (Fig. 5a-f). The results indicate that over-expression of INSM1 reduces cyclin D1 expression in club cells and CCSP-promoter active bronchial epithelial cells suggesting the reduction of cyclin D1 expression could cause cell cycle arrest and decreased cell proliferation.

\section{Ectopic expression of INSM1 suppresses cyclin D1 and} induces cell cycle arrest in normal human bronchial epithelial cells, BEAS-2B

Down regulation of cyclin D1 causes cell cycle arrest and interferes with bronchiolar epithelial cell proliferation. We used Ad-INSM1 or Ad-LacZ to infect a normal bronchial epithelial cell line, BEAS-2B. The results showed that over-expression of INSM1 caused the decrement of cyclin D1 (Fig. 5g). In vitro data of INSM1 suppressing cyclin D1 expression is consistent with the observation in our bi-transgenic mouse model where reduced cyclin D1 expression was seen in bronchial epithelial cells and club cells. To further support our hypothesis on the functional effects of INSM1 on bronchial epithelial cell growth, we over-expressed INSM1 

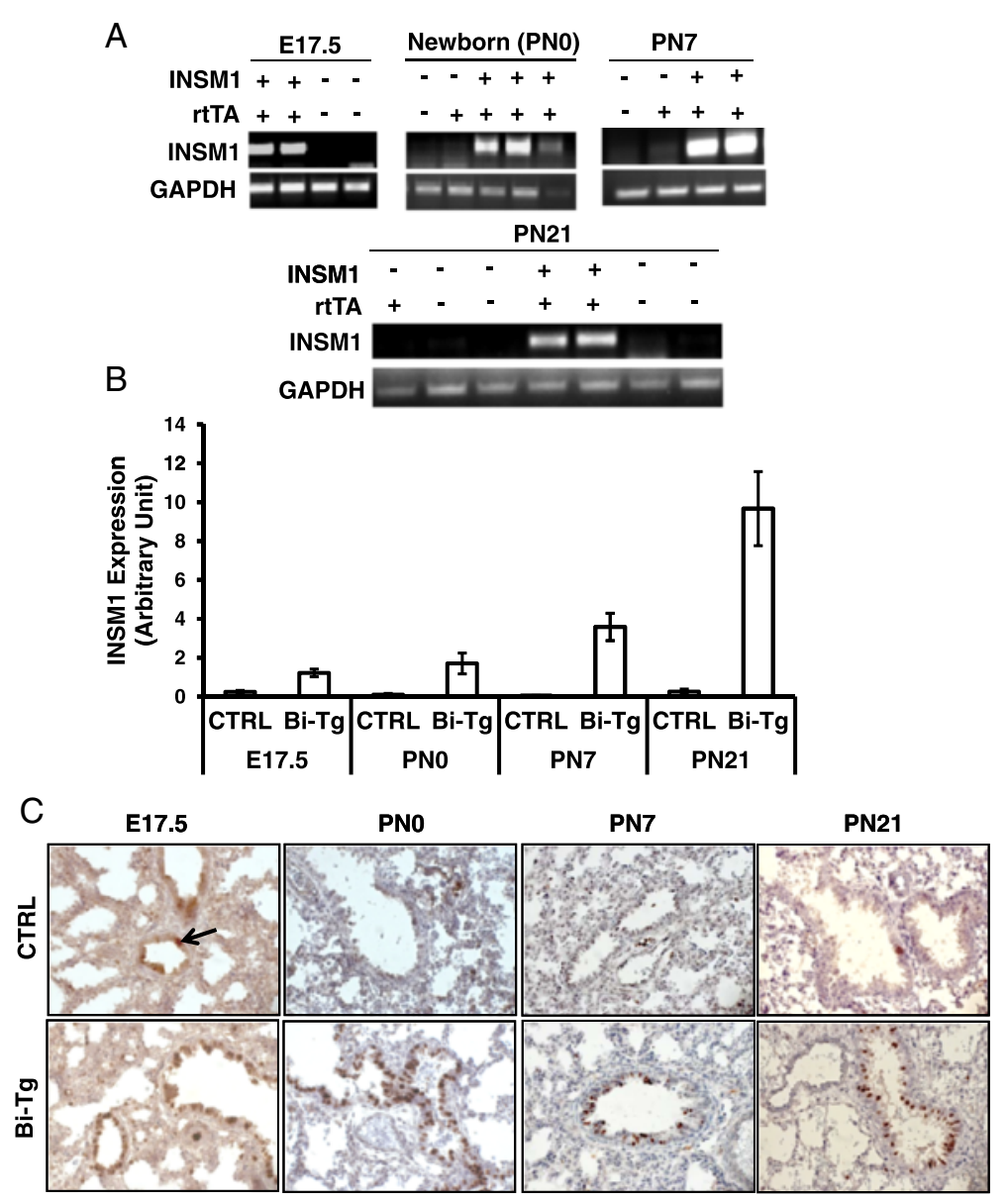

Fig. 3 Expression of INSM1 in developing lung. a INSM1 transgene expression was detected by RT-PCR. b Relative quantities of INSM1 transcript was normalized with internal control, GAPDH. c Immunohistochemical staining for INSM1 protein. INSM1 transgene expression in Bi-Tg lung was readily detected in E17.5, newborn (PN0), postnatal day 7 (PN7), and PN 21. Endogenous INSM1 expression was detected in E17.5 (arrow) but scarcely in post-natal lung. Results were represented from at least three mice

in BEAS cells for $24 \mathrm{~h}$ in serum-free medium followed by serum stimulation at various time points and analyzed the cell growth with a MTS assay and flow cytometric analysis with propidium iodide staining. The MTS assay showed that INSM1 caused cell death starting at $48 \mathrm{~h}$, as compared to the vehicle treated group. A statistically significant decrement of cell viability was

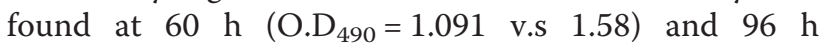
$\left(\mathrm{O}_{490}=1.61\right.$ v.s 2.21) (Fig. 6a). The Ad-INSM1 infected cells showed reduced cell proliferation, as $32.86 \%$ of the total population was found in the $G_{0} / G_{1}$ region as compared to $16.9 \%$ of control Ad-LacZ infected cells (Fig. $6 \mathrm{~b}$ ). In addition, the $G_{2} / M$ population of cells in the Ad-INSM1 infected sample decreased to $40.98 \%$ as compared to the Ad-LacZ control group, $54.18 \%$. This result suggests that over-expression of INSM1 caused cell cycle arrest at the $G_{0} / G_{1}$ phase probably through the reduction of cyclin D1 expression.

\section{Discussion}

We initiated our study to dissect the functional effect of INSM1 transcription factor in normal lung development since INSM1 is a sensitive and specific NE lung cancer marker [7]. Club cells were found in close association with NEBs, where PNECs are derived from common multi-potent stem cells in the airway epithelium which is highly related to the non-ciliated secretory club cells. During lung development and injury, PNECs transiently express CCSP which is a major product of the nonciliated progenitor cells for airway epithelium [3, 10]. Therefore, we chose CCSP-promoter driven ectopic expression of INSM1 as a model to reveal its functional effect during lung development. There are multiple genetically engineered mouse models for NE carcinomas of the lung [11]. The original $R b / p 53$ double knockout [12] or triple knockout (double knockout model plus loss of p130) [13] or loss of Pten [14, 15] models resulted in 


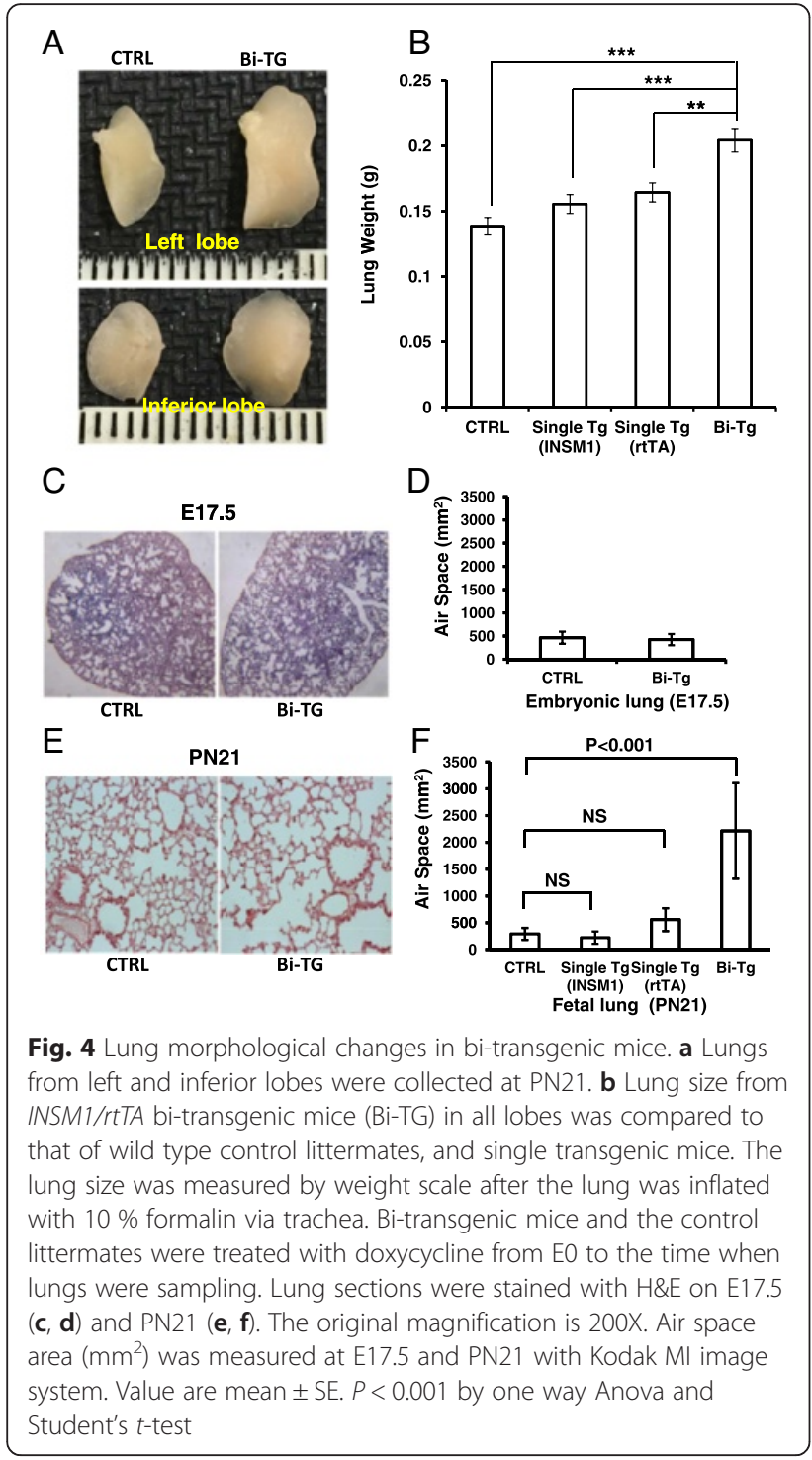

multiple pulmonary tumors arising mainly from the central large bronchi with foci of in situ carcinoma and NE cell hyperplasia. An additional model with constitutive co-expression of SV40 large $\mathrm{T}$ antigen and human achaete-scute homolog-1 (hASH-1) generated adenocarcinomas with focal NE differentiation [16]. Solely ectopic expression of INSM1 in bronchial epithelial cell did not alter the lung epithelial cell toward NE differentiation. Whether the precursors were not properly targeted or ectopic expression of INSM1 is insufficient to induce $\mathrm{NE}$ differentiation and/or transformation is not known. The latter is more likely since constitutive expression of human achaete-scute homolog-1 (hASH-1) in combination with simian virus large $\mathrm{T}$-antigen under the club cell CCSP-promoter resulted in adenocarcinomas with focal NE differentiation [16]. The expression of

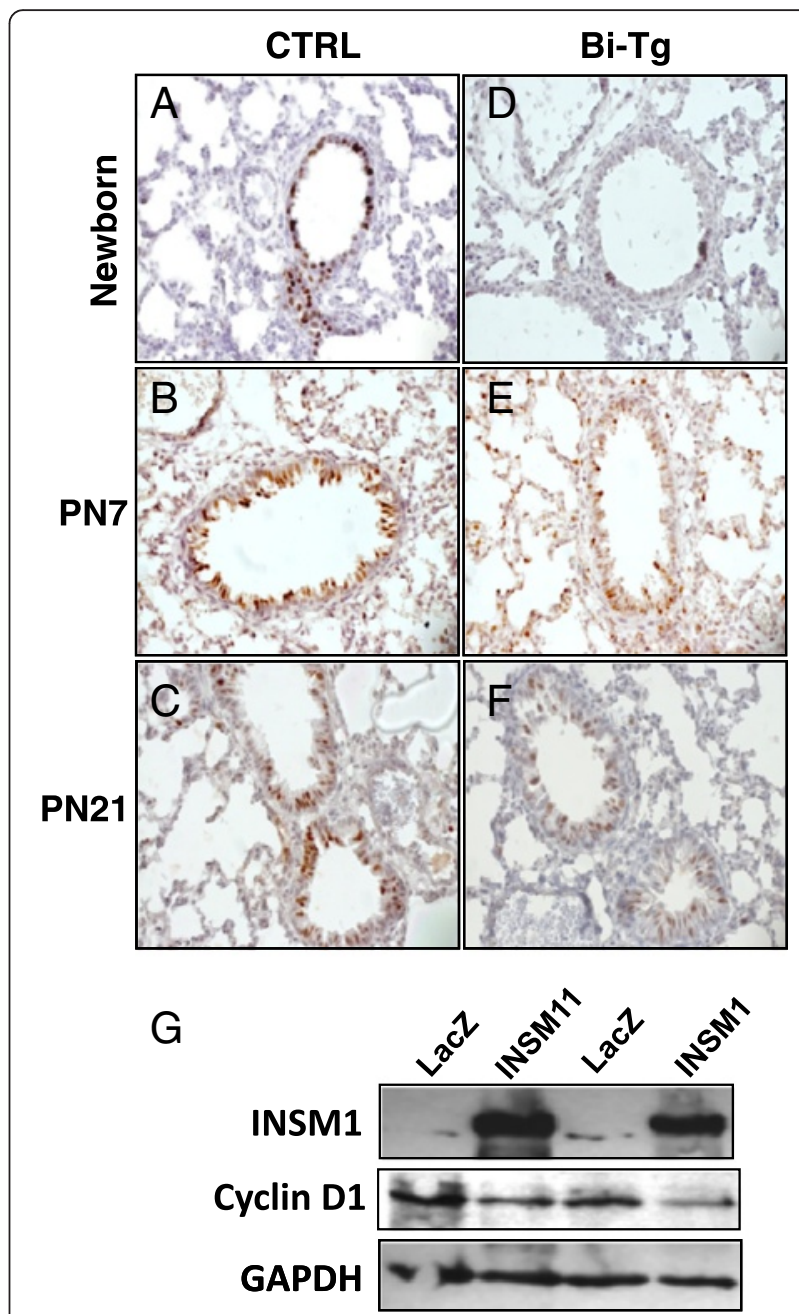

Fig. 5 INSM1 ectopic expression suppresses cyclin D1 expression in bronchial epithelial cells. Immunohistochemical staining for cyclin D1, weaker and stronger positive signal were detected in the nuclei of bronchial epithelial cells in bi-transgenic mice (d-f) as compared to the control (a-c) on PNO, PN7, and PN21. Original magnification is 400X. g A human bronchial epithelial cell line, BEAS-2B, was infected with Ad-INSM1 or Ad-LacZ for $24 \mathrm{~h}$ and cultured in DMEM medium with $10 \%$ fetal bovine serum for 14 or $24 \mathrm{~h}$. The cell lysate was measured by Western blot analysis for INSM1 and cyclin D1 using housekeeping protein GAPDH as an internal control. Similar results were observed from three separated experiments

Mash1 and Insm 1 are closely associated with NE differentiation [17].

This study revealed that INSM1 did not induce NE precursor differentiation instead it resulted in alveolar space enlargement and bronchial epithelial cell cycle arrest through down regulation of cyclin D1. One prominent function of club cells is to restore and renew the bronchiolar epithelial cells. Alveolar formation occurs at the final stage of lung development as the process begins at embryonic day 21 and continues entirely as a postnatal event in mice. Alveologenesis involves the septation 


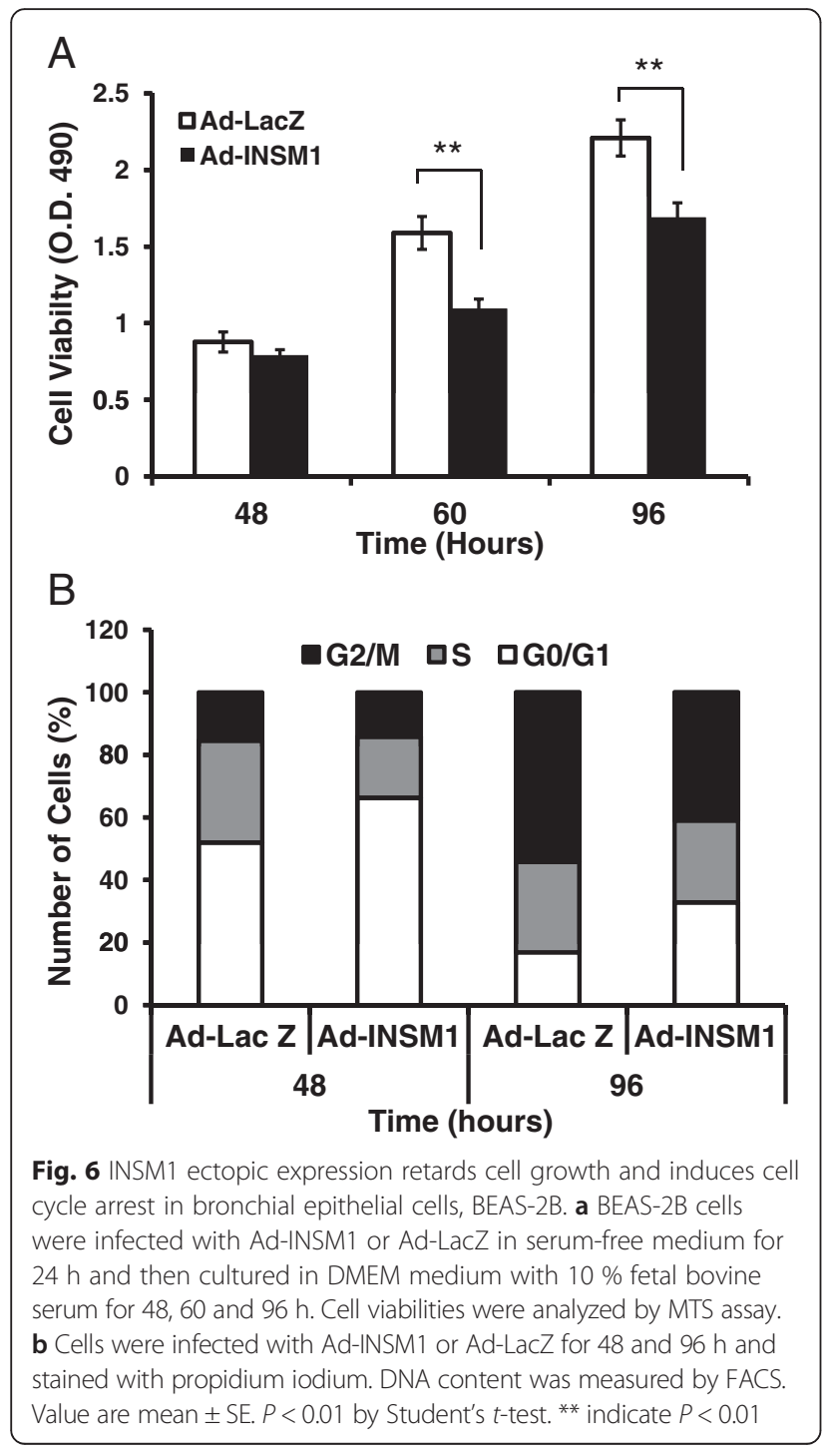

of alveolar saccules into mature alveoli, which increases surface area and enhances the oxygen exchange capacity of the lung [18]. Cuboidal respiratory epithelial cell differentiation and proliferation play important roles in the septation process. Disruption of the process leads to alveolar hypoplasia that is characteristic in enlarged and simplified alveoli [19-21]. Down regulation of cyclin D1 will cause cell cycle arrest and decrease cell proliferation. Sequentially, less bronchiolar epithelial cells in the INSM1 over-expressed lung interrupt the repair and regeneration of the new bronchiolar epithelium and cause the air sac enlargement. Altered cyclin and Cdk expression consistent with G1 or G2 arrest has been reported in epithelial cells in the premature baboon model of BronchoPulmonary Dysplasia (BPD), a chronic lung disease that occurs in the premature infants and is characterized by impaired alveologenesis [22]. This result is consistent with our previous study that INSM1 induces
non-NE cell cycle arrest by blocking the cyclin D1 and CDK4 interaction [23].

\section{Conclusion}

A NE lung tumor marker was conditionally induced to express during lung development. The bi-transgenic animal model revealed that ectopic expression of INSM1 under the CCSP-promoter resulted in impairment of alveologenesis by increasing the air sac and causes alveolar hypoplasia. The defect is potentially caused by the reduction of cyclin D1 and cell cycle arrest during new bronchiolar epithelium regeneration.

\section{Ethics approval and consent to participate}

Human small cell lung carcinoma tissue array (LC802b) was used in this study. Each specimen collected from any clinic was consented to by both hospital and individual. Discrete legal consent form was obtained and the rights to hold research uses for any purpose or further commercialized uses were waived (US Biomax, Rockville, MD). An IRB exemption (\#8885) was obtained from Louisiana State University Health Sciences Center, New Orleans.

Animals were maintained in a pathogen-free vivarium in filtered cages according to the protocol approved by Institutional Animal Care and Use Committee from the Research Institute for Children, Children's Hospital in New Orleans.

\section{Consent for publication \\ Not applicable.}

\section{Availability of data and materials}

Data and materials will be available for public upon request.

\section{Abbreviations}

CCSP: club cell secretory protein; Dox: doxycycline; hASH-1: human achaetescute homolog-1; INSM1: insulinoma-associated 1; NE: neuroendocrine; NEBs: neuro-epithelial bodies; PNECs: pulmonary neuroendocrine cells; SCLC: small cell lung cancer.

Competing interests

Authors have no competing interests to declare.

\section{Authors' contributions}

MBB and MSL conceptualized and designed the project. CC and MSL acquired the data and performed data analysis. MBB and CC generated animal model. CC, MBB, and MSL prepared and reviewed the manuscript. All authors read and approved the final manuscript.

\section{Acknowledgements}

The project was supported in part from Children's Hospital New Orleans.

\section{Funding}

The study was funded by the Research Institute for Children, Children's Hospital, New Orleans. 


\section{Author details}

'Research Institute for Children, Children's Hospital, 200 Henry Clay Avenue, Research and Education Building, Room. 2211, New Orleans, LA 70118, USA. ${ }^{2}$ Departments of Pediatrics, Louisiana State University Health Sciences Center, New Orleans, LA 70112, USA. ³epartments of Genetics, Louisiana State University Health Sciences Center, New Orleans, LA 70112, USA.

Received: 10 December 2015 Accepted: 4 April 2016

Published online: 12 April 2016

\section{References}

1. Rawlins EL, Ostrowski LE, Randell SH, Hogan BL. Lung development and repair: contribution of the ciliated lineage. Proc Natl Acad Sci U S A. 2007; 104:410-7.

2. Peake JL, Reynolds SD, Stripp BR, Stephens KE, Pinkerton KE. Alteration of pulmonary neuroendocrine cells during epithelial repair of naphthaleneinduced airway injury. Am J Pathol. 2000;156:279-86.

3. Reynolds SD, Hong KU, Giangreco A, Mango GW, Guron C, Morimoto Y, Stripp BR. Conditional club cell ablation reveals a self-renewing progenitor function of pulmonary neuroendocrine cells. Am J Physiol Lung Cell Mol Physiol. 2000;278:L1256-63.

4. Goto Y, DeSilva MG, Toscani A, Prabhakar BS, Notkins AL, Lan MS. A novel human insulinoma-associated CDNA, IA-1, encodes a protein with zincfinger DNA-binding motifs. J Biol Chem. 1992;267:15252-7.

5. Lan MS, Li Q, Lu J, Modi WS, Notkins AL. Genomic organization, 5'-upstream sequence, and chromosomal localization of an insulinoma-associated intronless gene, IA-1. J Biol Chem. 1994;269:14170-4.

6. Lan MS, Breslin MB. Structure, expression, and biological function of INSM1 transcription factor in neuroendocrine differentiation. FASEB J. 2009;23: 2024-33.

7. Lan MS, Russell EK, Lu J, Johnson BE, Notkins AL. IA-1, a new marker for neuroendocrine differentiation in human lung cancer cell lines. Cancer Res. 1993;53:4169-71.

8. Wolf M, Holle R, Hans K, Drings P, Havemann K. Analysis of prognostic factors in 766 patients with small cell lung cancer (SCLC): the role of sex as a predictor for survival. Br J Cancer. 1991;63:986-92.

9. Hackett BP, Gitlin JD. Cell-specific expression of a Club cell secretory protein-human growth hormone gene in the bronchiolar epithelium of transgenic mice. Proc Natl Acad Sci U S A. 1992;89:9079-83.

10. Castro CM, Yang Y, Zhang Z, Linnoila Rl. Attenuation of pulmonary neuroendocrine differentiation in mice lacking Club cell secretory protein. Lab Invest. 2000;80:1533-40.

11. Gazdar AF, Savage TK, Johnson JE, Berns A, Sage J, Linnoila RI, MacPherson D, McFadden DG, Farago A, Jacks T, Travis WD, Brambilla E. The comparative pathology of genetically engineered mouse models for neuroendocrine carcinomas of the lung. J Thorac Oncol. 2015;10:553-64.

12. Meuwissen R, Linn SC, Linnoila Rl, Zevenhoven J, Mooi WJ, Berns A. Induction of small cell lung cancer by somatic inactivation of both Trp53 and Rb1 in a conditional mouse model. Cancer Cell. 2003;4:181-9.

13. Schaffer BE, Park KS, Yiu G, Conklin JF, Lin C, Burkhart DL, Karnezis AN, Sweet-Cordero EA, Sage J. Loss of p130 accelerates tumor development in a mouse model for human small-cell lung carcinoma. Cancer Res. 2010;70: 3877-83.

14. Cui M, Augert A, Rongione M, Conkrite K, Parazzoli S, Nikitin AY, Ingolia N, MacPherson D. PTEN is a potent suppressor of small cell lung cancer. Mol Cancer Res. 2014;12:654-9.

15. McFadden DG, Papagiannakopoulos T, Taylor-Weiner A, Stewart C, Carter SL, Cibulskis K, Bhutkar A, McKenna A, Dooley A, Vernon A, Sougnez C, Malstrom S, Heimann M, Park J, Chen F, Farago AF, Dayton T, Shefler E, Gabriel S, Getz G, Jacks T. Genetic and clonal dissection of murine small cell lung carcinoma progression by genome sequencing. Cell. 2014;156:1298-311.

16. Linnoila RI, Sahu A, Miki M, Ball DW, DeMayo FJ. Morphometric analysis of CC10-hASH1 transgenic mouse lung: a model for bronchiolization of alveoli and neuroendocrine carcinoma. Exp Lung Res. 2000;26:595-615.

17. Wildner $H$, Gierl MS, Strehle M, Pla P, Birchmeier C. Insm1 (IA-1) is a crucial component of the transcriptional network that controls differentiation of the sympatho-adrenal lineage. Development. 2008;135:473-81.

18. Ten Have-Opbroek AA. Lung development in the mouse embryo. Exp Lung Res. 1991;17:111-30.
19. Londhe VA, Maisonet TM, Lopez B, Jeng JM, Li C, Minoo P. A subset of epithelial cells with CCSP promoter activity participates in alveolar development. Am J Respir Cell Mol Biol. 2011:44:804-12.

20. Galambos C, deMello DE. Regulation of alveologenesis: clinical implications of impaired growth. Pathology. 2008;40:124-40.

21. Jobe AJ. The new BPD: an arrest of lung development. Pediatr Res. 1999;46:641-3.

22. Das KC, Ravi D. Altered expression of cyclins and cdks in premature infant baboon model of bronchopulmonary dysplasia. Antioxid Redox Signal. 2004:6:117-27.

23. Zhang T, Liu WD, Saunee NA, Breslin MB, Lan MS. Zinc-finger transcription factor INSM1 interrupts cyclin D1 and CDK4 binding and induces cell cycle arrest. J Biol Chem. 2009;284:5574-81.

\section{Submit your next manuscript to BioMed Central and we will help you at every step:}

- We accept pre-submission inquiries

- Our selector tool helps you to find the most relevant journal

- We provide round the clock customer support

- Convenient online submission

- Thorough peer review

- Inclusion in PubMed and all major indexing services

- Maximum visibility for your research

Submit your manuscript at www.biomedcentral.com/submit
Biomed Central 